\title{
Fortification of yogurts with different antioxidant preservatives: a comparative study between natural and synthetic additives
}

Running Title: Fortification of yogurts with different antioxidant preservatives

Cristina Caleja ${ }^{1,2,3}$, Lillian Barros ${ }^{1,2}$, Amilcar L. Antonio ${ }^{1}$, Márcio Carocho ${ }^{1}$, M. Beatriz P.P. Oliveira ${ }^{3}$, Isabel C.F.R. Ferreira ${ }^{1, *}$

${ }^{I}$ Mountain Research Centre (CIMO), ESA, Polytechnic Institute of Bragança, Campus de Santa Apolónia, 1172, 5301-855 Bragança, Portugal

${ }^{2}$ Laboratory of Separation and Reaction Engineering (LSRE), Associate Laboratory LSRE/LCM, IPB, Campus de Santa Apolónia, 1134, 5301-857 Bragança, Portugal. ${ }^{3}$ REQUIMTE - Science Chemical Department, Faculty of Pharmacy, University of Porto, Rua Jorge Viterbo Ferreira $n^{\circ} 228,4050-313$ Porto, Portugal

* Author to whom correspondence should be addressed (e-mail: iferreira@ipb.pt telephone $+351-273-303219$; fax +351-273-325405). 


\begin{abstract}
Consumers demand more and more so-called "natural" products and, therefore, the aim of this work was to compare the effects of natural versus synthetic antioxidant preservatives in yogurts. Matricaria recutita L. (chamomile) and Foeniculum vulgare Mill. (fennel) decoctions were tested as natural additives, while potassium sorbate (E202) was used as a synthetic additive. The fortification of yogurts with natural and synthetic antioxidants did not cause significant changes in the yoghurt $\mathrm{pH}$ and nutritional value, in comparison with control samples (yogurt without any additive). However, the fortified yogurts showed higher antioxidant activity, mainly the yogurts with natural additives (and among these, the ones with chamomile decoction). Overall, it can be concluded that plant decoctions can be used to develop novel yogurts, by replacing synthetic preservatives and improving the antioxidant properties of the final product, without changing the nutritional profile.
\end{abstract}

Keywords: Yogurt; Matricaria recutita; Foeniculum vulgare; potassium sorbate (E202); antioxidant preservatives. 


\section{Introduction}

Yogurt is a fermented dairy product obtained by lactic acid fermentation through the action of Lactobacillus delbrueckii ssp. bulgaricus and Streptococcus thermo-philus. The resulting lactic acid reacts with milk protein, promoting the characteristic texture and sensorial properties of this product (Serafeimidou, Zlatanos, Kritikos, \& Tourianis, 2013). Yogurts are highly appreciated, and since they are regarded as important in human diet, they are produced and consumed massively in many countries $\left(\mathrm{O}^{\prime}\right.$ Connel \& Fox, 2001; Serafeimidou et al., 2013; Shori \& Baba, 2014). However the literature points out that dairy food products have a limited content of bioactive compounds, which can remove some value from these products. Therefore, to overcome this limitation some authors suggest the incorporation of plant or fruits based additives to fortify the yogurt (Karaaslan, Ozden, Vardin, \& Turkoglu, 2011; Martins et al., 2014; Bertolino et al., 2015).

In the food industry, synthetic additives are used to improve the characteristics and properties of processed foods, and include preservatives (antimicrobials, antioxidants and antibrowning), nutritional additives and coloring, flavoring, texturizing and miscellaneous agents (Branen, Davidson, Salminen \& Thorngate, 2002; DicksonSpillmann, Siegrist \& Keller, 2011; Carocho, Barreiro, Morales \& Ferreira, 2014). However, many studies have confirmed that the excessive consumption of synthetic food additives is related with gastrointestinal, respiratory, dermatological, and neurological adverse reactions (Wilson \& Bahna, 2005; Randhawa \& Bahna, 2009; Carocho et al., 2014).

Potassium sorbate is one of the main preservatives used in food industry, being also extensively used as an antimicrobial agent since it can effectively inhibit the growth of fungi, aerobic bacteria and yeasts (Karabulut, Lurie \& Droby, 2001; Fandos \& 
Dominguez, 2007; Liu, Wang \& Young, 2014). Despite being considered as safe, effective, and presenting a lower toxicity than other preservatives (Karabulut et al., 2001; Karabulut, Romanazzi, Smilanick \& Lichter, 2005; Fandos and Dominguez, 2007), some authors consider that the use of this preservative has adverse effects on human health (Kamankesh, Mohammadi, Tehrani, Ferdowsi \& Hosseini, 2013). In particular, some cases of allergic effects have been described, such as urticaria and asthma (Code of Federal Regulations, 1999, Tfouni \& Toledo, 2002; Goren et al., 2015), and also cases of intolerance (Code of Federal Regulations, 1999; Hannuksela \& Haahtela, 1987; Goren et al., 2015).

Antioxidants present in plants, algae and mushrooms are excellent natural additives and have been presented as alternatives to synthetic additives. Vitamins, polyphenols and carotenoids are considered the most natural antioxidant molecules (Baines \& Seal, 2012; Carocho \& Ferreira, 2013a; Carocho, Morales \& Ferreira, 2015). Due to their high antioxidant power, the polyphenols are considered among the most interesting and relevant natural compounds to be used as food preservatives and bioactive ingredients (Caleja et al., 2015a; Caleja et al., 2015b; Carocho et al., 2015).

The antioxidant and antimicrobial potential of Matricaria recutita L. (chamomile) and Foeniculum vulgare Mill. (fennel) decoctions (rich in phenolic compounds such as quercetin-3-O-glucoside and 5-O-caffeolylquinic acid, or di-caffeoyl-2,7-anhydro-3deoxy-2-octulopyranosonic acid and luteolin-O-glucuronide, respectively) was previously demonstrated by our research group, as well as their efficient use as preservatives in cottage cheese (Caleja et al., 2015a; Caleja et al., 2015b). The aim of the present study was to propose the use of these polyphenol rich extracts to yogurts, and to compare their performance with a synthetic additive commonly used in dairy products. 


\section{Materials and methods}

\subsection{Standards and reagents}

Acetonitrile was of HPLC grade from Fisher Scientific (Lisbon, Portugal). Fatty acids methyl ester (FAME) reference standard mixture 37 (standard 47885-U) was purchased from Sigma-Aldrich (St. Louis, Missouri, USA), as also sugar standards. 2,2-Diphenyl1-picrylhydrazyl (DPPH) was obtained from Alfa Aesar (Ward Hill, Massuchets, USA). Water was treated in Milli-Q water purification system (Millipore Corporation, Billerica, Massachusetts, USA).

\subsection{Natural and synthetic additives}

Dried samples of Matricaria recutita L. (chamomile) and Foeniculum vulgare Mill. (fennel) were provided by Américo Duarte Paixão Lda. (Alcanede, Portugal). In order to prepare the decoction extracts, the samples were reduced to powder ( $\sim 20$ mesh) and added $(5 \mathrm{~g})$ to $200 \mathrm{~mL}$ of distilled water. The mixture was heated (VELP Scientific plate, Usmate, Italy), allowed to boil for 5 minutes and then left to stand for $5 \mathrm{~min}$, filtered, frozen and lyophilized (FreeZone 4.5, Labconco, Kansas City, Missouri, USA). The lyophilized extracts obtained by the described decoction procedure were used as natural additives. The characterisation of the extracts in terms of individual phenolic compounds was previously carried out by HPLC-DAD-ESI/MS and described by the authors (Caleja et al., 2015a; Caleja et al., 2015b). Five flavonoids (mainly quercetin-3$O$-glucoside) and twelve phenolic acids (mainly 5-O-caffeolylquinic acid) were found in fennel extract (Caleja et al., 2015a), while di-caffeoyl-2,7-anhydro-3-deoxy-2octulopyranosonic acid and luteolin- $O$-glucuronide were identified as the main phenolic compounds present in the chamomile extract (Caleja et al., 2015b). 
The synthetic additive used was potassium sorbate 99\% (E202) and it was supplied by Acros organics (Geel, Belgium).

\subsection{Fortification of yogurts with the natural and synthetic additives}

Four groups of samples were prepared (yogurts with $100 \mathrm{~g}$ each): control samples (yogurts without additives); samples with potassium sorbate (E202); samples with the fennel decoction; and samples with the chamomile decoction. For each portion of $100 \mathrm{~g}$ of yogurt, $40 \mathrm{mg}$ of the additive (natural or synthetic) were incorporated. All the yogurts were prepared in duplicate.

Yogurts were prepared from UHT (ultra high temperature) milk (fat 3.6\%; protein 3.3\% and carbohydrates 5.0\%) mixed with natural yogurt purchased at the local market. After fortification with the different additives, each corresponding sample was left for overnight incubation at $44{ }^{\circ} \mathrm{C}$ for yogurt production.

2.4. Nutritional composition, physico-chemical analyses and evaluation of the antioxidant activity of the samples along shelf life

The samples were analyzed immediately after preparation and after seven and fourteen days of storage at $4{ }^{\circ} \mathrm{C}$. All the analyses were performed in triplicate.

2.4.1. Nutritional parameters. The samples were also analyzed for proximate composition (moisture, protein, fat, ash and carbohydrates) using the AOAC (2005) procedures. The crude protein content $(\mathrm{N} \times 6.38)$ of the samples was estimated by Kjeldahl method; the crude fat was determined by extracting a known weight of powdered sample with petroleum ether, using a Soxhlet apparatus; the ash content was determined by incineration at $600 \pm 15^{\circ} \mathrm{C}$ and total carbohydrates were calculated by difference. Total energy was calculated according to the following equation: Energy 
$(\mathrm{kcal})=4 \times(\mathrm{g}$ proteins $+\mathrm{g}$ carbohydrates $)+9 \times(\mathrm{g}$ lipids $)$. Free sugars were detected by HPLC coupled to refraction index detector and the identification was performed by comparison with standards, and further quantified ( $\mathrm{g} / 100 \mathrm{~g}$ of yogurt) by using an internal standard (melezitose). Fatty acids were analyzed by GC coupled to a FID detector and the identification was performed by comparison with commercial standards. Results were expressed in relative percentage of each fatty acid.

2.4.2. Physico-chemical parameters. The color of the samples was measured in six different points (three on the top and three on bottom), for each sample, by using a colorimeter (model CR-400, Konica Minolta Sensing Inc., Tokyo, Japan). Using the illuminant $\mathrm{C}$ and diaphragm aperture of $8 \mathrm{~mm}$, the CIE $L^{*} a^{*} b^{*}$ color space values were registered using a data software "Spectra Magic Nx" (version CM-S100W 2.03.0006) (Fernandes, Antonio, Barreira, Oliveira, Martins \& Ferreira, 2012).

The $\mathrm{pH}$ of the samples was measured directly in the samples with a HI $99161 \mathrm{pH}-$ meter (Hanna Instruments, Woonsocket, Rhode Island, USA).

2.4.3. Antioxidant activity. The lyophilized samples (3 g) were extracted with methanol/water (80:20) at room temperature during $1 \mathrm{~h}$ under stirring. The extract was filtered with Whatman paper filter $\mathrm{N}^{\mathrm{o}} 4$ (Sigma-Aldrich, Missouri, USA) and the remaining solid residue subjected to an additional extraction at the same conditions. The resulted extracts were evaporated under reduced pressure in a rotatory evaporator until complete removal of methanol. Finally, the evaporated extract was dissolved in methanol at a concentration of $200 \mathrm{mg} / \mathrm{mL}$ for the antioxidant activity evaluation. DPPH radical-scavenging activity and reducing power were evaluated at 515 and 690 nm, respectively, using ELX800 microplate Reader (Bio-Tek Instruments, Inc., Winooski, Vermont, USA) (Caleja et al., 2015a). 


\subsection{Statistical analysis}

The data were expressed as means \pm standard deviation. An analysis of variance (ANOVA) with type III sums of squares was carried out in the SPSS software. By using a multivariate general linear model, the dependent variables were analyzed through a 2way ANOVA with the factors "incorporation" (I) and "storage time" (ST). When a significant interaction was detected for both factors (I and ST), they were evaluated simultaneously by the estimated marginal means. If no statistical significant interaction was detected, the means were compared using Tukey's multiple comparison test, relying on a previous assessment of the equality of variances through the Levene's test. All statistical tests were performed at a 5\% significance level and using the SPSS software, version 22 (IBM Corp., USA).

\section{Results and discussion}

The four types of yogurts; control, fortified with E202, fennel and chamomile were labeled, and analyzed after three storage periods (0,7 and 14 days). The results are presented in Tables 1 to 4 . The results are presented as the mean value of each storage time (ST) regardless of the fortification treatment, and also the mean value of each fortification (F) regardless of the storage time. With this type of statistical analysis and representation, the best fortification type (control, E202, fennel decoction and chamomile decoction) could be determined independently of the storage time, but also the influence of the storage time irrespectively of the incorporation type. Thus, the standard deviations should not be regarded as a measure of accuracy of the methodologies, given that they encompass the results of the non-fixed factor (F or ST). Furthermore, the interaction among both factors $(\mathrm{ST} \times \mathrm{F})$ could also be determined 
through this study. Every time a significant interaction was detected $(p<0.05)$, no multiple comparisons could be carried out, therefore, the influence of each factor could be evaluated from the Whisker Box Plots representation, first for all samples then for all storage times. Table 1 shows the nutritional parameters, the energy value and the individual sugars, detected through HPLC-RI, expressed in $\mathrm{g} / 100 \mathrm{~g}$ of fresh weight. Overall, and as expected, moisture and fat were the most abundant nutrients in the yoghurts. For the majority of the parameters, the interaction between ST and F was significant, with only moisture not showing significant interaction. In terms of the individual factors, their effect was significant in most cases, except moisture, proteins and carbohydrates, concerning the effect of F. Thus, the fortification type has lower influence than the storage time on these parameters. Overall, none of the incorporations had a significant influence on the nutritional profile of the yogurts.

Moisture and protein values are in agreement with the results reported by Serafeimidou et al. (2013), in yogurts prepared with cow and sheep milk; however, ash values were higher than the ones described by these authors. Two free sugars were quantified in the studied samples: lactose and galactose (Table 1). The changes in these two sugars are not drastic, regardless of the fortification applied. Previous studies focused on the influence of the addition of different halzenut skins to yogurts have described the presence of these two sugars as well as glucose, although it was detectedin very low amounts (Bertolino et al., 2015).

The twelve most abundant fatty acids detected in the yogurt samples are presented in Table 2. It was possible to identify twenty-three fatty acids in the studied samples, the remaining eleven were detected in trace amounts (data no shown). The most abundant ones were oleic acid (C18:1n9), followed by palmitic acid (C16:0), stearic acid (C18:0) and myristic acid (C14:0). As expected, saturated fatty acids prevailed over unsaturated 
ones, with the monounsaturated showing higher amounts than polyunsaturated. The variation among SFA and PUFA was very slight, both along storage time and with the different fortification types. Among the presented fatty acids, a significant interaction among ST and F was found for all of them. In terms of C15:0 and C16:1, storage time had a higher impact than the fortification type and, inversely, for C18:1n9 (the most abundant fatty acid), the highest contributing factor for its variation was the fortification type, expressed by the respective p-values for each factor (Table 2). In 2001, Serafeimidou et al. (2013) described the same trends in terms of abundancies (SFA $>$ MUFA $>$ PUFA), but identified a higher number of fatty acids.

The results of two physico-chemical parameters (color and $\mathrm{pH}$ ) of the yogurts are displayed in Table 3. For all parameters, the interaction was significant $(p<0.05)$, but some general tendencies could be extracted from the Whisker Box Plot representation. The incorporations did not alter the color parameters of the yogurts to the naked eye, as can be confirmed in Figure 1. For color parameters it was not observed a significant change in $\mathrm{L}^{*}$ (lightness) in the different samples and along storage time. The a* value has a minor contribution for total color, but has the same tendency as $\mathrm{L}^{*}$ value. The samples with no added extract, with E202 and with Fennel were not significantly different regarding color parameters (graphs not shown). A slight distinctive mark was observed only for yogurts with chamomile fortification in $b^{*}$ parameter (Figure 2-A). In food industry, color control is used to produce another product for the market and could also be used as a control quality parameter along expected storage time. Its change along storage is not desired, however different color products, as is current in food industry, namely in yogurts, are a distinctive mark. 
In a similar study with yoghurts fortified with grape (Vitis vinifera) seed extracts, the same tendency was observed, as the supplementation with seed extracts did not affect the $\mathrm{pH}$ values of the yogurts however, the color of different seeds (Agiorgitiko and Moschofilero seed extracts were red and yellow, respectively) affected the color of the yogurts, which was not visually detected (Chouchouli et al., 2013). Another study with yogurts fortified with bioactive compounds obtained from different grape varieties, presented positive values of $\mathrm{a}^{*}$ and displayed light red color (Karaaslan et al., 2011).

In terms of the $\mathrm{pH}$ values, none of the fortifications changed the parameters, which is quite important to maintain the yogurts' stability during the storage time. The values are also within the acceptable range and in accordance with previously published studies with the same foodstuffs (Ersöz, Kınık, Yerlikaya \& Açu, 2011; Serafeimidou et al., 2013; Bertolino et al., 2015). According to Gohil, Ahmed, Davies and Robinson (1995), the analysis of this parameter in yogurts is very important with respect to public safety. The same authors report that pathogens such as Listeria monocytogenes in yogurts die out rapidly at $\mathrm{pH}$ values between 4.2 and 4.5. Another study reported the survival of Salmonella and Escherichia coli for up to 10 and 7 days respectively, at high $\mathrm{pH}$ values in yoghurts (Massa, Altieri \& Quaranta de Pace, 1997).

The results of the reducing power and DPPH radical scavenging activity of the yogurt samples along shelf life are given in Table 4. Once again, the interaction among the storage time and fortification type was significant, therefore, tendencies were extracted from the Whisker Box Plots representation of all data regardless storage time (Figure 2B). Similar analysis was performed for all samples at different storage times without significant differences being observed. Still, by interpreting the table, the best assay was the reducing power, given the lower $\mathrm{EC}_{50}$ values. Yogurts fortified with fennel and chamomile decoctions seem to have conferred a higher antioxidant capacity to the 
yogurts than the synthetic additive, as can be confirmed on Figures 2-B and 2-D, although it was more apparent for the reducing power assay. Figure 2-B represents the box-plot representation for the reducing power for each incorporation for all the storage times. It is clear that, for the results expressed in $\mathrm{EC}_{50}$ values, yogurts incorporated with chamomile displayed the highest activity, lower $\mathrm{EC}_{50}$ values, followed by fennel incorporations. As expected, the control samples showed the lower reducing power capacity. Interestingly, the antioxidant capacity of the yogurts fortified with the chemical additive, lost their antioxidant capacity more rapidly than the plant fortified yogurts, mainly from the seventh day of storage onwards, proving the excellent capacity of the plants, especially over longer periods of storage, as could be seen from the graphic bars for all fortifications at each storage time (Figure 2-C). Figure 2-D represents the box-plot graphs for each fortification for all the storage times, except for the DPPH assay. Once again, chamomile decoction was the best antioxidant, although the chemical additive showed a very similar activity as fennel incorporated yogurts. Still, after the seventh day, the antioxidant capacity of the yogurts fortified with the chemical additive lost considerable antioxidant capacity, while the fortified with natural products, although they lost some antioxidant capacity, this reduction was very slight (Figure 2-E).

Similar studies describe that the antioxidant activity of yogurts was enhanced by the presence of natural extracts, for example, in studies with yogurts fortified with white and red dragon fruit (Zainoldin and Baba, 2009), callus (Karaaslan et al, 2011), grape seed (Chouchouli et al., 2013) or with wild blackberry (Martins et al, 2014) extracts.

\section{Conclusions}


Yogurt is a highly appreciated product all over the world and, concomitantly, dairy industry is in constant research for innovative products. So, yogurts fortified with antioxidants from natural origin are an interesting food to satisfy consumer demands for healthy products. This study revealed that the introduction of aqueous extracts prepared from plants improves the antioxidant activity of yoghurts, showing higher capacity than the synthetic additive, potassium sorbate, used as antioxidant preservative by the food industry, including the dairy sector. Furthermore, the incorporation of these decoctions did not significantly alter the nutritional profile, external appearance, $\mathrm{pH}$ and individual fatty acids, proving that natural plant extracts are beneficial for consumers and do not pose nutritional changes in the yogurts during their normal storage period.

\section{Acknowledgements}

The authors are grateful to the Foundation for Science and Technology (FCT, Portugal) for C. Caleja (SFRH/BD/93007/ 2013) and L. Barros (SFRH/BPD/107855/2015) grants. The authors also thank Ms Clarinda Paixão, from Américo Duarte Paixão Lda, Portugal, for providing the plant samples.

\section{References}

AOAC. (2005). Official methods of analysis of AOAC international. In W. Horwitz, \& G. Latimer (Eds.) (18th ed.). Gaithersburg, MD: AOAC International.

Baines, D. \& Seal, R. (2012). Natural food additives, ingredients and flavourings. Cambridge, UK: Woodhead Publishing.

Barros, L., Pereira, E., Calhelha, R.C., Dueñas, M., Carvalho, A.M., Santos-Buelga, C., \& Ferreira, I.C.F.R. (2013). Bioactivity and chemical characterization in 
hydrophilic and lipophilic compounds of Chenopodium ambrosioides L. Journal of Functional Foods, 5, 1732-1740.

Branen, A.L., Davidson, P.M., Salminen, S. \& Thorngate, J.H. (2002). Food additives (2nd ed.). New York: Marcel Dekker, Inc..

Bertolino, M., Belviso, S., Dal Bello, B., Ghirardello, D., Giordano, M., Rolle, L., Gerbi, V., \& Zeppa, G. (2015). Influence of the addition of different hazelnut skins on the physicochemical, antioxidant, polyphenol and sensory properties of yogurt. LWT - Food Science and Technology, 63, 1145-1154.

Caleja, C., Barros, L., Antonio, A.L., Ciric, A., Soković, M., Oliveira, M.B.P.P., Santos-Buelga, C., \& Ferreira, I.C.F.R. (2015a). Foeniculum vulgare Mill. as natural conservation enhancer and health promoter by incorporation in cottage cheese. Journal of functional foods, 12, 428-438.

Caleja, C., Barros, L., Antonio, A.L., Ciric, A., Barreira, J.C.M. Soković, M., Oliveira, M.B.P.P., Santos-Buelga, C., \& Ferreira, I.C.F.R. (2015b). Development of a functional dairy food: exploring bioactive and preservation effects of chamomile (Matricaria recutita L.). Journal of functional foods, 16, 114-124.

Carocho, M. \& Ferreira, I.C.F.R. (2013a). A review on antioxidants, prooxidants and related controversy: natural and synthetic compounds, screening and analysis methodologies and future perspectives. Food and Chemical Toxicology, 51:1525.

Carocho, M., \& Ferreira, I. C. F. R. (2013b). The role of phenolic compounds in the fight against cancer e a review. Anti-Cancer Agents in Medicinal Chemistry, 13, $1236-1258$. 
Carocho, M., Barreiro, M.F., Morales, P. \& Ferreira, I.C.F.R. (2014). Adding molecules to food, pros and cons: A review on synthetic and natural food additives. Comprehensive reviews in food science and food safety, 13, 377-399.

Carocho, M., Morales, P. \& Ferreira, I.C.F.R. (2015). Natural food additives: Quo vadis? Trends in Food Science \& Technology, 45, 284-295.

Chouchouli, V., Kalogeropoulos, N., Konteles, S. J., Karvela, E., Makris, D. P. and Karathanos, V. T. (2013). Fortification of yoghurts with grape (Vitis vinifera) seed extracts. LWT - Food Science and Technology, 53, 522-529).

Code of Federal Regulations. (1999). Title 21, US Government Printing Office, Washington, DC, Revised 1, Section:184.1733, sodium benzoate, Section:182.3640, potassium sorbate.

Dickson-Spillmann, M., Siegrist, M. \& Keller, C. (2011). Attitudes toward chemicals are associated with preference for natural food. Food Quality and Preference, 22, $149-156$.

Ersöz, E., Kınık, Ö., Yerlikaya, O. \& Açu, M. (2011). Effect of phenolic compounds on characteristics of strained yoghurts produced from sheep milk. African Journal of Agricultural Research, 6(23), 5351-5359.

Fandos, G.E. \& Dominguez, J.L. (2007). Effect of potassium sorbate washing on the growth of Listeriamonocytogenes on fresh poultry. Food Control, 18 (7), 842846.

Fernandes, Â., Antonio, A.L., Barreira, J.C.M., Oliveira, M.B.P.P., Martins, A., \& Ferreira, I.C.F.R. (2012). Effects of gamma irradiation on physical parameters of Lactarius deliciosus wild edible mushrooms. Postharvest Biology and Technology, 74, 79-84. 
Gohil, V.S., Ahmed, M.A., Davies, R. and Robinson, R.K. (1995). The incidence of Listeria in foods in the United Arab Emirates. Journal of Food Protection, 58(1), 102-104.

Goren, A.C., Bilsel, G., Şimşek, A., Bilsel, M., Akcadağ, F., Topal, K. \& Ozgen, H., (2015). HPLC and LC-MS/MS methods for determination of sodium benzoate and potassium sorbate in food and beverages: Performances of local accredited laboratories via proficiency tests in Turkey. Food Chemistry, 175, 273-279.

Hannuksela, M. \& Haahtela, T. (1987). Hypersensitivity reactions to food additives. Allergy, 42(8), 561-575.

Kamankesh, M., Mohammadi, A., Tehrani, Z. M., Ferdowsi, R. \& Hosseini, H. (2013) Dispersive liquid-liquid microextraction followed by high-performance liquid chromatography for determination of benzoate and sorbate in yogurt drinks and method optimization by central composite design. Talanta, 109, 46-51.

Karaaslan, M., Ozden, M., Vardin, H., \& Turkoglu H. (2011). Phenolic fortification of yogurt using grape and callus extracts. LWT - Food Science and Technology, 44, 1065-1072.

Karabulut, O. A., Lurie, S. \& Droby, S. (2001). Evaluation of the use of sodium bicarbonate, potassium sorbate and yeast antagonists for decreasing postharvest decay of sweet cherries. Postharvest Biol. Technol,. 23 (3), 233-236.

Karabulut, O.A., Romanazzi, G., Smilanick, J.L.\& Lichter, A., 2005. Postharvest ethanol and potassium sorbate treatments of table grapes to control gray mold. Postharvest Biol. Technol. 37 (2), 129-134.

Liu, K., Wang, X. \& Young, M. (2014). Effect of bentonite/potassium sorbate coatings on the quality of mangos in storage at ambient temperature. Journal of Food Engineering, 137, 16-22. 
Martins, A., Barros, L., Carvalho, A.M. Santos-Buelga, C., Fernandes, I.P., Barreiro F., \& Ferreira, I.C.F.R. (2014). Phenolic extracts of Rubus ulmifolius Schott flowers: characterization, microencapsulation and incorporation into yogurts as nutraceutical sources. Food \& Function, 5, 1091-1100.

Massa, S., Altieri, V. and Quaranta de Pace, R. (1997). Surviaval of Eschericha coli 0157:H7 in yoghurt during preperation and storage at $4{ }^{\circ} \mathrm{C}$. Letters in Appplied Microbiology, 24(5), 347-350.

O’Connell, J. E., \& Fox, P. F. (2001). Significance and applications of phenolic compounds in the production and quality of milk and dairy products: a review. International Dairy Journal, 11, 103-120.

Randhawa, S. \& Bahna, S. L. (2009). Hypersensitivity reactions to food additives. Current Opinion in Allergy and Clinical Immunology, 9(3), 278.

Serafeimidou, A., Zlatanos, S., Kritikos, G., \& Tourianis, A. (2013). Change of fatty acid profile, including conjugated linoleic acid (CLA) content, during refrigerated storage of yogurt made of cow and sheep milk. Journal of Food Composition and Analysis, 31, 24-30.

Shori, A. \& Baba A. S. (2014). Comparative antioxidant activity, proteolysis and in vitro $\alpha$-amylase and $\alpha$-glucosidase inhibition of Allium sativum-yogurts made from cow and camel milk. Journal of Saudi Chemical Society, 18, 456-463.

Tfouni, S. A. \& Toledo, M. C. (2002). Estimates of the mean per capita daily intake of benzoic and sorbic acids in Brazil. Food Additives \& Contaminants, 19(7), 647654.

Wilson, B. G. \& Bahna, S. L. (2005). Adverse reactions to food additives. Annals of Allergy, Asthma \& Immunology, 95(6), 499-507. 
Zainoldin, K. H., \& Baba, A. S. (2009). The effect of Hylocereus polyrhizus and Hylocereus undatus on physicochemical, proteolysis, and antioxidant activity in yogurt. Engineering and Technology, 60, 361-366. 
Table 1. Macronutrients, free sugars composition $(\mathrm{g} / 100 \mathrm{~g})$ and energy value (kcal/100 g) of the yogurts along shelf life and with different fortifications.

\begin{tabular}{|c|c|c|c|c|c|c|c|c|c|}
\hline & & Moisture & Fat & Protein & Ash & Carbohydrates & Energy & Galactose & Lactose \\
\hline \multirow{3}{*}{$\begin{array}{l}\text { Storage time } \\
(\mathrm{ST})\end{array}$} & 0 days & $87.6 \pm 0.2 b$ & $2.58 \pm 0.18$ & $3.92 \pm 0.12$ & $0.67 \pm 0.02$ & $5.25 \pm 0.4$ & $60 \pm 1$ & $0.49 \pm 0.10$ & $3.28 \pm 0.13$ \\
\hline & 7 days & $87.5 \pm 0.3 \mathrm{a}$ & $2.42 \pm 0.23$ & $3.77 \pm 0.10$ & $0.70 \pm 0.02$ & $5.62 \pm 0.33$ & $59 \pm 2$ & $0.56 \pm 0.07$ & $2.96 \pm 0.28$ \\
\hline & 14 days & $87.3 \pm 0.8 \mathrm{ab}$ & $2.32 \pm 0.13$ & $3.84 \pm 0.05$ & $0.70 \pm 0.02$ & $5.79 \pm 0.81$ & $60 \pm 3$ & $0.62 \pm 0.09$ & $2.78 \pm 0.32$ \\
\hline \multirow[t]{2}{*}{$p$-value $(\mathrm{n}=24)$} & Tukey's HSD test & 0.036 & $<0.001$ & $<0.001$ & 0.001 & 0.005 & $<0.001$ & $<0.001$ & $<0.001$ \\
\hline & Control & $87.6 \pm 0.5$ & $2.55 \pm 0.22$ & $3.81 \pm 0.04$ & $0.70 \pm 0.03$ & $5.39 \pm 0.66$ & $60 \pm 2$ & $0.54 \pm 0.10$ & $2.98 \pm 0.20$ \\
\hline \multirow{3}{*}{$\begin{array}{l}\text { Fortification } \\
\text { (F) }\end{array}$} & E202 & $87.4 \pm 0.7$ & $2.38 \pm 0.22$ & $3.87 \pm 0.08$ & $0.68 \pm 0.02$ & $5.64 \pm 0.73$ & $59 \pm 3$ & $0.44 \pm 0.05$ & $2.74 \pm 0.4$ \\
\hline & Fennel decoction & $87.3 \pm 0.5$ & $2.54 \pm 0.16$ & $3.91 \pm 0.12$ & $0.70 \pm 0.02$ & $5.57 \pm 0.52$ & $61 \pm 2$ & $0.62 \pm 0.09$ & $3.13 \pm 0.25$ \\
\hline & Chamomile decoction & $87.6 \pm 0.3$ & $2.30 \pm 0.13$ & $3.79 \pm 0.14$ & $0.67 \pm 0.02$ & $5.62 \pm 0.31$ & $58 \pm 2$ & $0.63 \pm 0.02$ & $3.18 \pm 0.01$ \\
\hline$\overline{p \text {-value }(\mathrm{n}=18)}$ & Tukey's HSD test & 0.058 & $<0.001$ & 0.098 & $<0.001$ & 0.606 & $<0.001$ & $<0.001$ & $<0.001$ \\
\hline$\overline{\mathrm{ST}} \times \mathrm{F}(\mathrm{n}=72)$ & $p$-value & 0.086 & $<0.001$ & $<0.001$ & $<0.001$ & 0.016 & $<0.001$ & $<0.001$ & $<0.001$ \\
\hline
\end{tabular}

In each row and within each storage period, different letters mean significant statistical differences between control yogurts, yogurts with E202, yogurts with fennel decoction and yogurts with chamomile decoction $(p<0.05)$. 
Table 2. Fatty acids composition of the yogurts (expressed in relative percentage of each fatty acid) along shelf life and with different fortifications.

\begin{tabular}{|c|c|c|c|c|c|c|c|c|c|c|c|c|c|c|c|c|}
\hline & & C4:0 & C6:0 & C8:0 & C10:0 & C12:0 & C14:0 & C15:0 & C16:0 & C16:1 & C18:0 & C18:1n9 & C18 :2n9 & SFA & MUFA & PUFA \\
\hline \multirow{3}{*}{$\begin{array}{l}\text { Storage time } \\
\text { (ST) }\end{array}$} & 0 days & $3.4 \pm 0.5$ & $2.8 \pm 0.3$ & $1.5 \pm 0.2$ & $2.7 \pm 0.2$ & $3.4 \pm 0.2$ & $10.7 \pm 0.3$ & $1.05 \pm 0.02$ & $32.9 \pm 0.5$ & $1.60 \pm 0.02$ & $11.1 \pm 0.2$ & $24 \pm 2$ & $2.7 \pm 0.2$ & $70 \pm 2$ & $26 \pm 2$ & $3.1 \pm 0.4$ \\
\hline & 7 days & $2.5 \pm 0.3$ & $2.4 \pm 0.3$ & $1.4 \pm 0.2$ & $2.7 \pm 0.2$ & $3.4 \pm 0.1$ & $10.9 \pm 0.2$ & $1.06 \pm 0.01$ & $33.5 \pm 0.7$ & $1.60 \pm 0.07$ & $11.2 \pm 0.3$ & $24 \pm 1$ & $2.4 \pm 0.3$ & $70 \pm 1$ & $27 \pm 1$ & $2.8 \pm 0.4$ \\
\hline & 14 days & $3.1 \pm 0.8$ & $2.4 \pm 0.1$ & $1.3 \pm 0.2$ & $2.6 \pm 0.3$ & $3.4 \pm 0.3$ & $10.9 \pm 0.4$ & $1.07 \pm 0.03$ & $33.8 \pm 0.5$ & $1.61 \pm 0.06$ & $11.3 \pm 0.2$ & $23.5 \pm 0.8$ & $2.4 \pm 0.4$ & $71 \pm 1$ & $26 \pm 1$ & $2.8 \pm 0.5$ \\
\hline$p$-value $(\mathrm{n}=24)$ & Tukey's HSD test & 0.001 & $<0.001$ & $<0.001$ & $<0.001$ & $<0.001$ & $<0.001$ & $<0.001$ & $<0.001$ & $<0.001$ & $<0.001$ & 0.051 & $<0.001$ & $<0.001$ & 0.025 & $<0.001$ \\
\hline \multirow{4}{*}{$\begin{array}{l}\text { Fortification } \\
\text { (F) }\end{array}$} & Control & $2.9 \pm 0.6$ & $2.6 \pm 0.3$ & $1.5 \pm 0.1$ & $2.8 \pm 0.2$ & $3.6 \pm 0.2$ & $11.1 \pm 0.3$ & $1.08 \pm 0.02$ & $33.2 \pm 0.3$ & $1.58 \pm 0.04$ & $11.0 \pm 0.1$ & $24 \pm 1$ & $2.3 \pm 0.4$ & $71 \pm 1$ & $27 \pm 1$ & $2.6 \pm 0.4$ \\
\hline & E202 & $3.4 \pm 0.7$ & $2.6 \pm 0.5$ & $1.5 \pm 0.4$ & $2.7 \pm 0.3$ & $3.4 \pm 0.2$ & $10.8 \pm 0.1$ & $1.05 \pm 0.02$ & $33.2 \pm 0.7$ & $1.59 \pm 0.08$ & $11.1 \pm 0.3$ & $24 \pm 1$ & $2.5 \pm 0.2$ & $71 \pm 1$ & $26 \pm 1$ & $3.0 \pm 0.2$ \\
\hline & Fennel decoction & $3.2 \pm 0.6$ & $2.4 \pm 0.2$ & $1.3 \pm 0.1$ & $2.6 \pm 0.2$ & $3.3 \pm 0.2$ & $10.7 \pm 0.3$ & $1.05 \pm 0.02$ & $33.7 \pm 0.4$ & $1.63 \pm 0.02$ & $11.4 \pm 0.2$ & $23 \pm 1$ & $2.6 \pm 0.3$ & $71 \pm 1$ & $26 \pm 1$ & $3.1 \pm 0.4$ \\
\hline & Chamomile decoction & $2.6 \pm 0.5$ & $2.6 \pm 0.2$ & $1.3 \pm 0.1$ & $2.6 \pm 0.1$ & $3.3 \pm 0.1$ & $10.8 \pm 0.4$ & $1.06 \pm 0.03$ & $33.6 \pm 1.0$ & $1.61 \pm 0.04$ & $11.3 \pm 0.2$ & $24 \pm 1$ & $2.6 \pm 0.4$ & $70 \pm 2$ & $27 \pm 1$ & $3.1 \pm 0.4$ \\
\hline$p$-value $(\mathrm{n}=18)$ & Tukey's HSD test & $<0.001$ & 0.006 & $<0.001$ & $<0.001$ & $<0.001$ & $<0.001$ & 0.329 & $<0.001$ & 0.205 & $<0.001$ & $<0.001$ & $<0.001$ & $<0.001$ & $<0.001$ & 0.001 \\
\hline$\overline{S T} \times \mathrm{F}(\mathrm{n}=72)$ & $p$-value & $<0.001$ & $<0.001$ & $<0.001$ & $<0.001$ & $<0.001$ & $<0.001$ & $<0.001$ & $<0.001$ & $<0.001$ & $<0.001$ & $<0.001$ & $<0.001$ & $<0.001$ & $<0.001$ & $<0.001$ \\
\hline
\end{tabular}

The results are presented as mean \pm SD. Butiric acid (C4:0); Caproic acid (C6:0); Caprylic acid (C8:0); Capric acid (C10:0); Lauric acid (C12:0); Myristic acid (C14:0);

Pentadecanoic acid (C15:0); Palmitic acid (C16:0); Palmitoleic acid (C16:1); Stearic acid (C18:0); Oleic acid (C18:1n9); Linoleic acid (C18:2n6); SFA- Saturated fatty acids;

MUFA- Monounsaturated fatty acids; PUFA- Polyunsaturated fatty acids. 
Table 3. Color parameters and $\mathrm{pH}$ of the yogurts along shelf life and with different fortifications.

\begin{tabular}{llllll}
\hline & & $\mathrm{L}^{*}$ & $\mathrm{a}^{*}$ & $\mathrm{~b}$ & $\mathrm{pH}$ \\
\hline Storage time & 0 days & $92 \pm 1$ & $-2.7 \pm 0.8$ & $10 \pm 1$ & $4.4 \pm 0.1$ \\
$(\mathrm{ST})$ & 7 days & $93 \pm 1$ & $-2.7 \pm 0.4$ & $10 \pm 1$ & $4.5 \pm 0.1$ \\
& 14 days & $92 \pm 1$ & $-3.0 \pm 0.4$ & $10 \pm 1$ & $4.5 \pm 0.1$ \\
\hline$p$-value (n=24) & Tukey's HSD test & $<0.001<0.001$ & $<0.001$ & 0.001 \\
\hline & Control & $92 \pm 1$ & $-3.0 \pm 0.3$ & $8.8 \pm 0.5$ & $4.5 \pm 0.4$ \\
Fortification & E202 & $92 \pm 1$ & $-3 \pm 1$ & $9.7 \pm 0.7$ & $4.60 \pm 0.06$ \\
$($ F) & Fennel decoction & $92 \pm 1$ & $-2.6 \pm 0.3$ & $10.5 \pm 0.7$ & $4.3 \pm 0.1$ \\
& Chamomile decoction & $91 \pm 2$ & $-2.6 \pm 0.5$ & $11.5 \pm 0.7$ & $4.53 \pm 0.07$ \\
\hline$p$-value (n=18) & Tukey's HSD test & $<0.001<0.001$ & $<0.001$ & $<0.001$ \\
\hline ST $\times \mathrm{F}(\mathrm{n}=72)$ & $p$-value & $<0.001<0.001$ & $<0.001$ & $<0.001$ \\
\hline
\end{tabular}

The results are presented as mean \pm SD. $L^{*}$ : Lightness, $a^{*}$ : red-green, $b^{*}:$ yellow-blue (color parameters). 
Table 4. Antioxidant activity of the yogurts (expressed in $\mathrm{EC}_{50}$ values, $\mathrm{mg} / \mathrm{mL}$ ) along shelf life and with different fortifications.

\begin{tabular}{llll}
\hline & & Reducing Power & DPPH scavenging activity \\
\hline Storage time & 0 days & $25 \pm 6$ & $105 \pm 54$ \\
$(\mathrm{ST})$ & 7 days & $26 \pm 6$ & $107 \pm 56$ \\
& 14 days & $27 \pm 6$ & $121 \pm 57$ \\
\hline$p$-value (n=27) & Tukey's HSD test & $<0.001$ & $<0.001$ \\
\hline \multirow{2}{*}{ Fortification } & Control & $32.4 \pm 0.4$ & $195 \pm 5$ \\
$($ F) & E202 & $29 \pm 2$ & $111 \pm 20$ \\
& Fennel decoction & $27 \pm 1$ & $94 \pm 4$ \\
\hline$p$-value $(\mathrm{n}=36)$ & Tukey's HSD test & $<0.001$ & $45 \pm 3$ \\
\hline $\mathrm{ST} \times \mathrm{F}(\mathrm{n}=108)$ & $p$-value & $<0.001$ & $<0.001$ \\
\hline
\end{tabular}

The results are presented as mean \pm SD. 


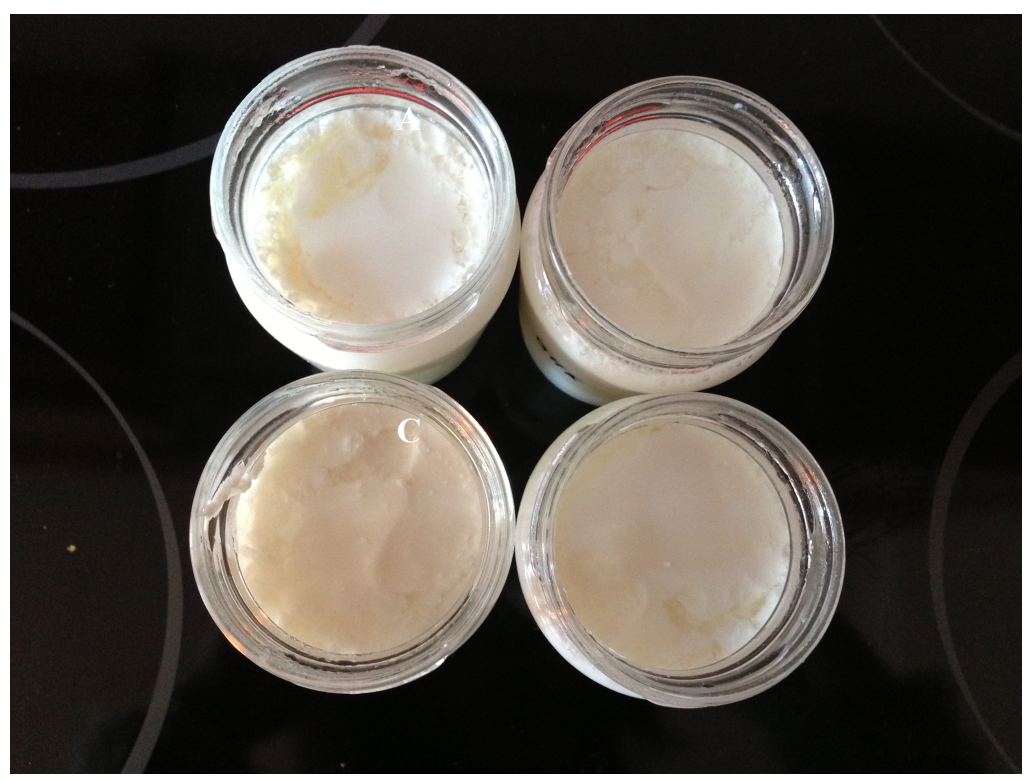

Figure 1. Visual appearance of different yogurt samples (A) Control yogurt, (B) yogurt with E202, (C) yogurt with fennel decoction and (D) yogurt with chamomile decoction. 


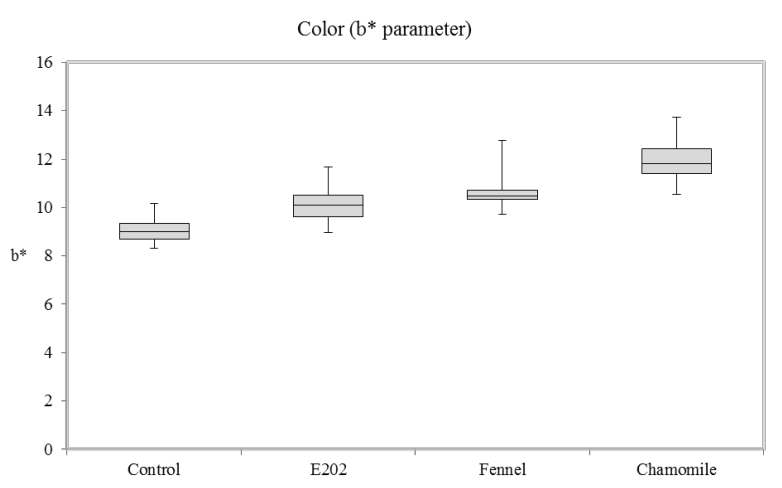

A
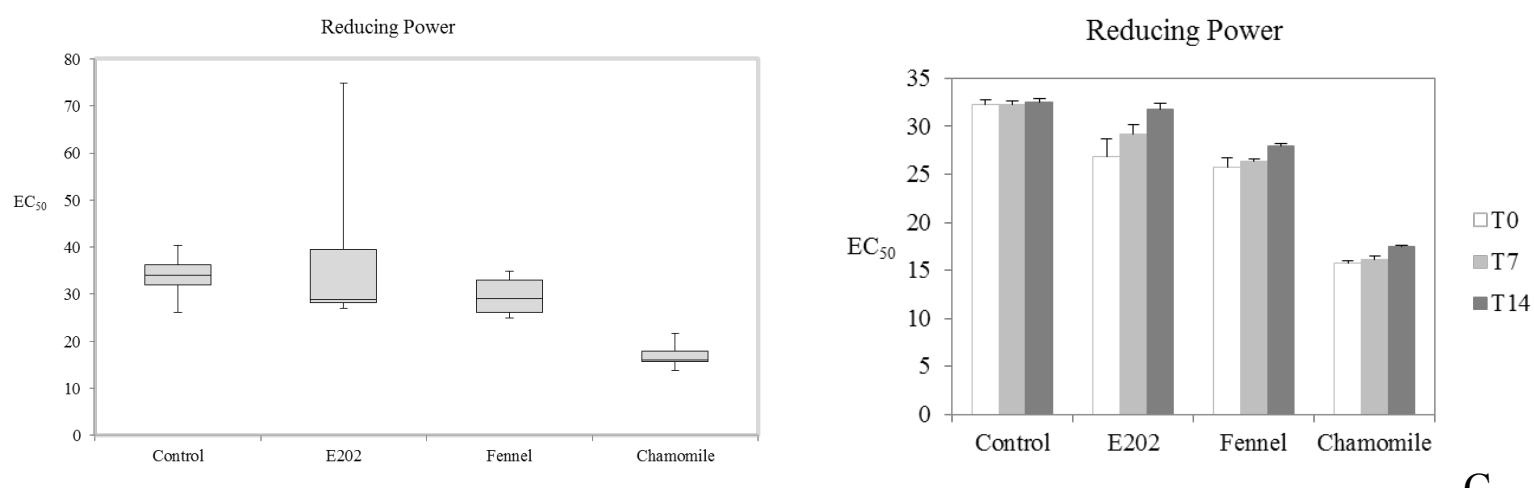

B

$\mathrm{C}$
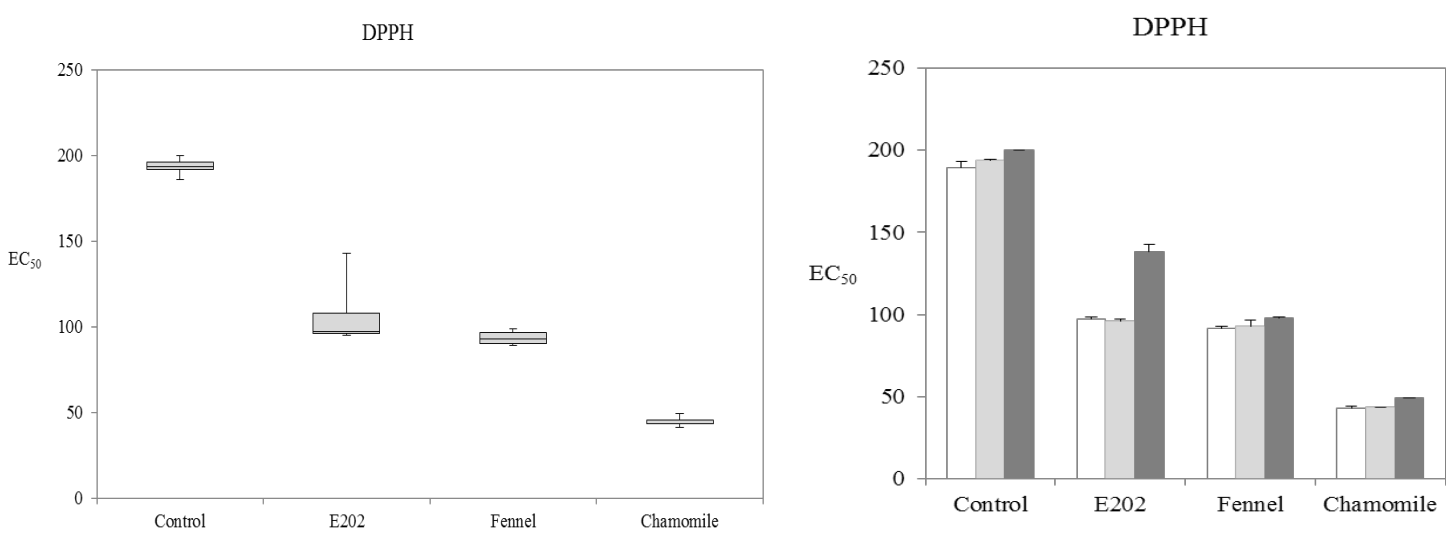

$\square \mathrm{TO}$

$\square \mathrm{T} 7$

$\because \mathrm{T} 14$

$\mathrm{D}$

$\mathrm{E}$

Figure 2. A- Color parameter ( $b^{*}$ value); B- Reducing Power assays whisker box plots; $\mathrm{C}$ - Reducing Power $\mathrm{EC}_{50}$ values for different samples at different storage times; DDPPH assays whisker box plots; E- DPPH $\mathrm{EC}_{50}$ values for the different samples at different storage times. 